\title{
CORRECTION
}

\section{Correction to: Prevalence, indications and demographic characteristics of Botulinum neurotoxin use in a tertiary oculoplastic centre}

\author{
Ian De Silva (D), Christina Lim (D), Mervyn Thomas, Antonella Berry-Brincat, Raghavan Sampath and Joyce Burns \\ (c) The Author(s), under exclusive licence to The Royal College of Ophthalmologists 2021
}

Eye (2022) 36:1520; https://doi.org/10.1038/s41433-021-01712-w

Correction to: Eye

https://doi.org/10.1038/s41433-021-01637-4
Unfortunately, in Table 1, on the last column, the rates should be written as per 100,000 instead of per 1000 .

The original article has been corrected. 